\title{
ZONEAMENTO DAS UNIDADES DE RELEVO DO MUNICÍPIO DE UNISTALDA - RS - BRASIL A PARTIR DE MODELAGEM DE PARÂMETROS MORFOMÉTRICOS EM SIG
}

\author{
Igor da Silva Knierin ${ }^{(a)}$, Romario Trentin ${ }^{(b)}$, Luís Eduardo de Souza Robaina ${ }^{(c)}$, Vinicius Silveira \\ dos Santos ${ }^{(d)}$
}

\footnotetext{
(a) Programa de Pós-Graduação em Geografia, Universidade Federal de Santa Maria, igorknierin@gmail.com

(b) Programa de Pós-Graduação em Geografia, Universidade Federal de Santa Maria, romario.trentin@gmail.com

(c) Programa de Pós-Graduação em Geografia, Universidade Federal de Santa Maria, lesrobaina@ yahoo.com.br

(d) Programa de Pós-Graduação em Geografia, Universidade Federal de Santa Maria, viniciusgeografia93@gmail.com
}

\section{Eixo: GEOTECNOLOGIAS E MODELAGEM ESPACIAL EM GEOGRAFIA}

\begin{abstract}
Resumo
Este trabalho apresentou como objetivo definir unidades de relevo do município de Unistalda - RS, com base em parâmetros morfométricos do relevo. Para seu desenvolvimento foi utilizado um Modelo Digital de Elevação (MDE) oriundo a imagens de RADAR SRTM de 3 arc-seconds (aproximadamente 90 metros) que foram processadas e modeladas em ambiente SIG (Sistema de Informação Geográfica), por meio do ArcGIS ${ }^{\circledR}$ 10.1. Desse modo, foi possível identificar áreas com características mínimas de heterogeneidade na paisagem, com padrões de formas e processos semelhantes, definidas em: Áreas Planas Associadas aos Cursos D’Água, Colinas com Cornijas, Colinas de Altitude, Morrotes Isolados e Associação de Morros e Morrotes. As informações obtidas a partir da modelagem do relevo com suporte do SIG foram satisfatórias, de acordo com as validações realizadas nos trabalhos de campo na área de estudo e seu produto final serve para indicar potencialidades e fragilidades naturais de cada unidade.
\end{abstract}

Palavras chave: Unidades de Relevo; Zoneamento; SIG; Morfometria

\section{Introdução}

As formas e o modelado do relevo correspondem ao resultado da atuação dinâmica e conjunta dos agentes endógenos e exógenos sobre a superfície da crosta terrestre, e assume para Casseti (1994) e Florenzano (2008), importante papel no processo de ocupação do espaço e dos diferentes ambientes.

Atualmente a utilização de Modelos Digitais de Elevação (MDE) juntamente com novas técnicas e produtos de Sensoriamento Remoto e Geoprocessamento com a participação dos Sistemas de Informações Geográficas (SIG) cria novas possibilidades por meio da extração e análise de variáveis topográficas com posterior tratamento e integração desses dados em ambiente computacional (VALERIANO, 2003; 2008), na identificação e estudo das formas do relevo. 


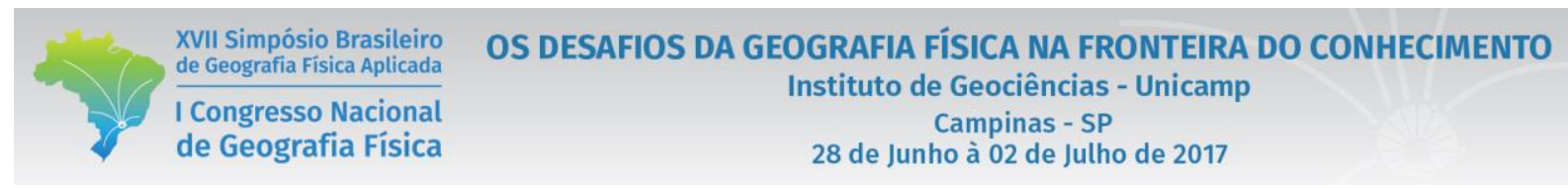

Desse modo, o estudo do relevo passa a apresentar novas dimensões, a medida em que suas análises descritivas se inserem com estudos integrados que consideram a complexidade das superfícies (SILVEIRA e SILVEIRA, 2013).

Estudos dessa natureza permitem diferentes aplicações, especialmente direcionadas ao planejamento e ordenamento territorial para orientar as formas de uso e ocupação da terra. Assim, corroboram para o planejamento tanto em áreas urbanas quanto rurais, conforme é retratado nos trabalhos de Girão e Corrêa (2004), Florenzano (2008), Santos Filho (2011), Guerra e Marçal (2014) e Ross (2014), entre outros.

Integrado a essa temática, o presente trabalho possui como objetivo o estudo das formas de relevo para o município de Unistalda - RS. A área de estudo localiza-se no Brasil Meridional, no segmento Centro-

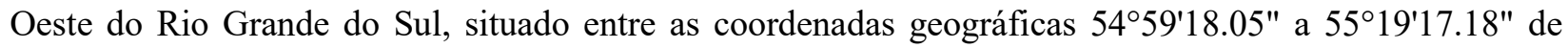
Longitude Oeste e 2856'06.99" a 29¹2'51.77" de Latitude Sul, de acordo com a Figura 1.

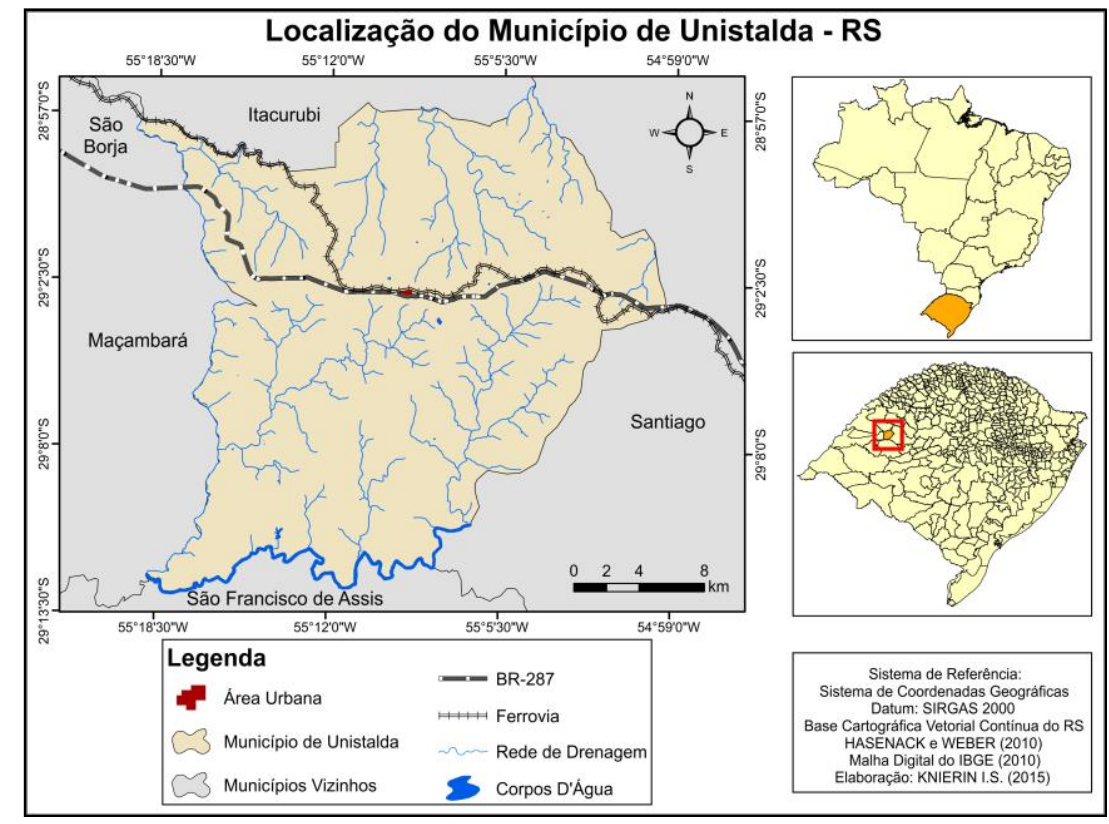

Figura 1 - Mapa de localização com a área urbana, principais vias de acesso e rede de drenagem do município de Unistalda - RS.

Fonte: KNIERIN, I.S. (2015).

\section{Metodologia}

Esse trabalho foi realizado a partir da modelagem em ambiente SIG (ArcGIS ${ }^{\circledR} 10.1$ - desenvolvido pela ESRI) de parâmetros morfométricos da rede drenagem (hirarquia fluvial e setorização de sistemas drenagem) e do relevo (hipsometria, declividade, amplitude e comprimento de vertente) do município de 
Unistalda - RS com a finalmente estabelecer áreas com características mínimas de heterogeneidade e dessa forma zonear unidades de relevo, de acordo com fluxograma da Figura 2.

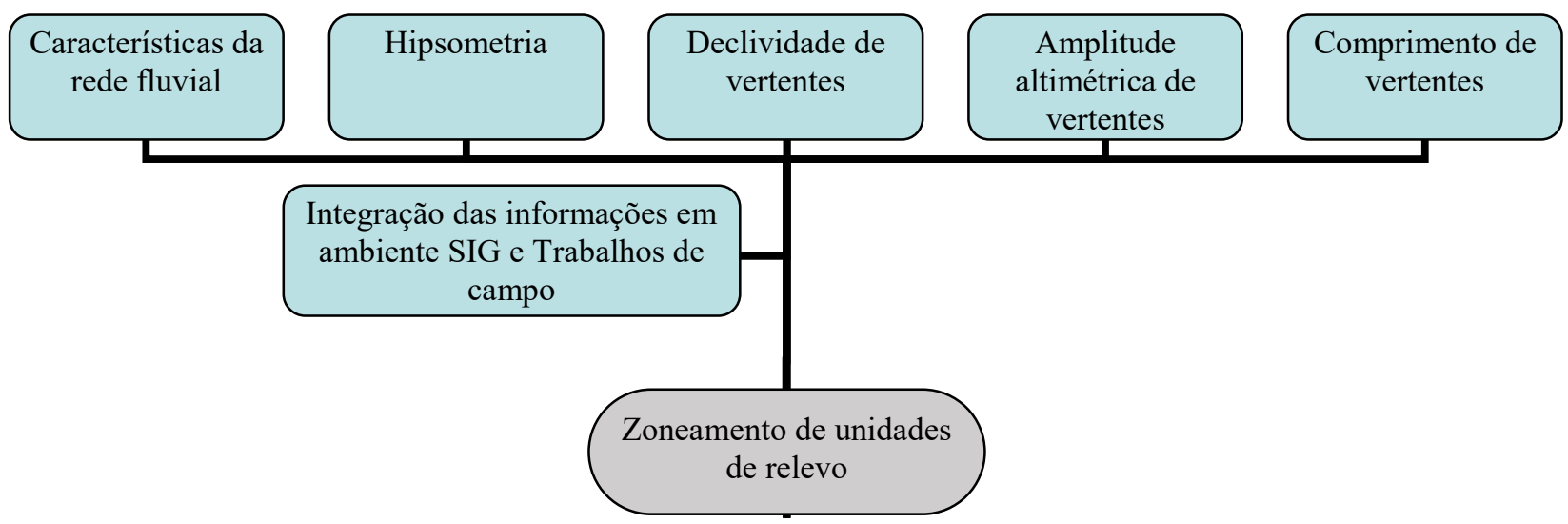

Figura 2 - Fluxograma indicando as etapas metodológicas de elaboração do zoneamento de unidades de relevo para o município de Unistalda - RS.

Fonte: KNIERIN, I.S. (2015).

Para análise morfométrica da rede de drenagem, procedeu-se levantamento de dados primários a partir da Base Cartográfica Vetorial Contínua do Rio Grande do Sul, organizada por Hasenack e Weber (2010), na escala 1:50.000. Em sequência, a base passou pelo processo de correção manual dos vetores - linhas e polígonos - correspondentes a rede de drenagem e aos corpos d'água, respectivamente. Nesse processo foi utilizado o ArcGIS ${ }^{\circledR} 10.1$ para as edições vetoriais e imagens de satélite ópticas do serviço Basemap World Imagery (constitui um banco de dados que integra imagens de satélite ópticas de diferentes fontes de dados e com escalas de até alta resolução espacial) disponível no SIG. Após isso, optou-se em compartimentar a área de estudo em sistemas de drenagem representativos conforme as dimensões da unidade territorial do município e pela hierarquia fluvial dos sistemas de drenagem de acordo com a classificação de Strahler (1952).

$\mathrm{Na}$ análise do relevo foi utilizado o ArcGIS ${ }^{\circ}$ 10.1, e como dados primários para modelagem do relevo imagens de RADAR, oriundas a missão Shuttle Radar Topography Mission (SRTM), com resolução espacial 3 Arc-Second $(90 \mathrm{~m}$ ), obtidas junto ao USGS (United States Geological Survey) que posteriormente foram processadas por meio da ferramenta Fill disponível no módulo Spatial Analyst do SIG. Foram adotados esses dados de base em função da melhor resposta ao que foi avaliado durante os trabalhos de campo na área de estudo (os trabalhos de campo são melhor retratados no final da metodologia). 


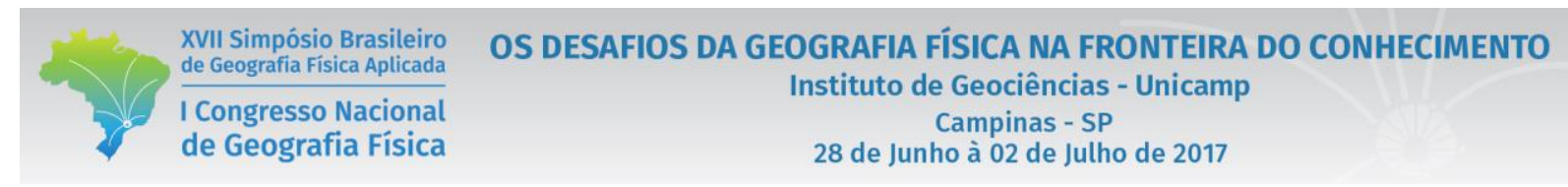

O mapa hipsométrico foi elaborado no ArcGIS ${ }^{\circledR} 10.1$ e foi adotada uma escala continua da hipsometria do menor ao maior valor da altitude definida no SIG com finalidade representativa por meio do editor da rampa de cores para raster (Stretched values along a colour ramp).

O mapa de declividade foi elaborado com a ferramenta Slope, disponível no módulo Spatial Analyst do ArcGIS ${ }^{\circledR}$ 10.1. Foram utilizados três limites de declividades (2\%, 5\% e 15\%) que estão associados ao desenvolvimento de processos de dinâmica superficial (IPT, 1981).

As amplitudes altimétricas e os comprimentos das vertentes foram obtidos a partir da elaboração e análise de perfis topográficos desenvolvidos com as ferramentas Interpolate Line e Profile Graph, no módulo $3 D$ Analyst do ArcGIS ${ }^{\circledR}$ 10.1. O layout final de quatros perfis topográficos mais representativos das diferentes formas do relevo na área de estudo foi organizado no software CorelDRAW® X5, desenvolvido pela Corel Corporation.

Para o zoneamento de unidades de relevo foi adaptado a proposta de classificação do Instituto de Pesquisas Tecnológicas de São Paulo (IPT, 1981), a partir da Tabela 1 e levou-se em consideração as variações de altitude no município. Foi utilizado para isso uma média altimétrica, com a cota de $250 \mathrm{~m}$ (ROBAINA et al, 2010), uma vez que, a mesma marca uma quebra natural do relevo na área de estudo formando, a partir desse patamar, uma linha de escarpas com direção Leste a Oeste.

Tabela 1 - Parâmetros utilizados para a classificação das formas de relevo para o município de Unistalda - RS.

\begin{tabular}{ccc}
\hline Formas de Relevo & Declividades & Amplitude Altimétrica \\
\hline Áreas planas associadas aos cursos d'água & $<5 \%$ & $<100 \mathrm{~m}$ \\
Colinas & $5-15 \%$ & $<100 \mathrm{~m}$ \\
Morrotes & $>15 \%$ & $<100 \mathrm{~m}$ \\
Morros & $>15 \%$ & $>100 \mathrm{~m}$ \\
\hline
\end{tabular}

Fonte: Adaptado do IPT (1981).

O zoneamento das unidades de relevo foi elaborado a partir do processo de vetorização manual de polígonos que representavam cada unidade seguindo como processo metodológico a interpolação dos layers dos mapas da rede de drenagem, hipsometria e de declividade, juntamente com a análise de curvas de nível (extraídas das imagens de RADAR SRTM, com resolução espacial 3 Arc-Second, de 90 m) para aferir a amplitude altimétrica das vertentes, dos perfis topográficos elaborados e de imagens de satélite ópticas disponibilizadas pelo serviço Basemap - World Imagery do ArcGIS® 10.1. Dessa forma, integrando essas informações identificou-se cinco áreas com características de homogeneidade na paisagem. 


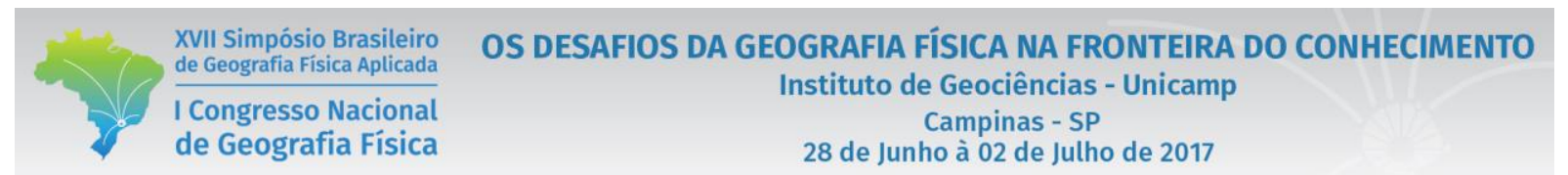

Com o objetivo de corroborar as informações apresentadas nos mapeamentos primários e final de zonamento das unidades de relevo, foram realizados trabalhos de campo na área de estudo, nos dias 29 e 30 de outubro de 2015, em estradas e caminhos em toda extensão no município de Unistalda - RS, na qual foram coletados pontos de controle com GPS, e identificado in loco as feições morfológicas, litologias, solos, uso e ocupação da terra e feições erosivas como ravinas e voçorocas.

\section{Resultados}

O município de Unistalda - RS está situado na Região Hidrográfica do Rio Uruguai e é drenado por duas grandes bacias de escala regional. Compreende, na sua porção Norte, a Bacia Hidrográfica do Rio Icamaquã - RS e a Bacia Hidrográfica do Rio Itu - RS ao Sul. Para esse estudo foram individualizadas seis áreas de drenagem, representadas a partir do Arroio Itu-Mirim, Arroio da Porteirinha, dos afluentes de até $3^{\circ}$ ordem do Rio Itu, do Arroio Iguariaçá, da Restinga de Santa Maria e dos afluentes de até $4^{\circ}$ ordem do Rio Itacurubi, conforme pode ser visualizado na Figura 3.

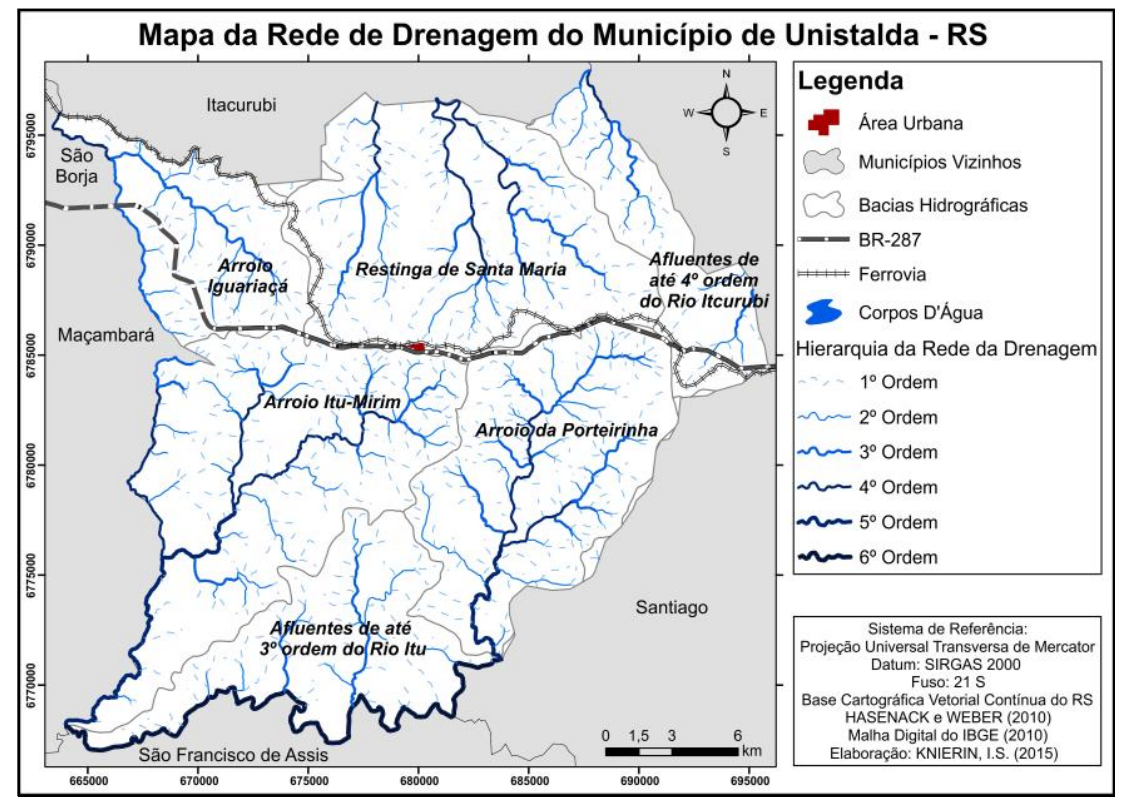

Figura 3 - Mapa da rede de drenagem com a hierarquia fluvial do município de Unistalda - RS.

Fonte: KNIERIN, I.S. (2015).

O estudo do relevo da área de estudo, foi realizado com base na análise integrada de variáveis morfométricas (hipsometria, declividade e amplitude e comprimento de vertentes), conforme retratado na metodologia de trabalho e apresentado nos mapas das Figuras 4 e 5, respectivamente com o mapa 


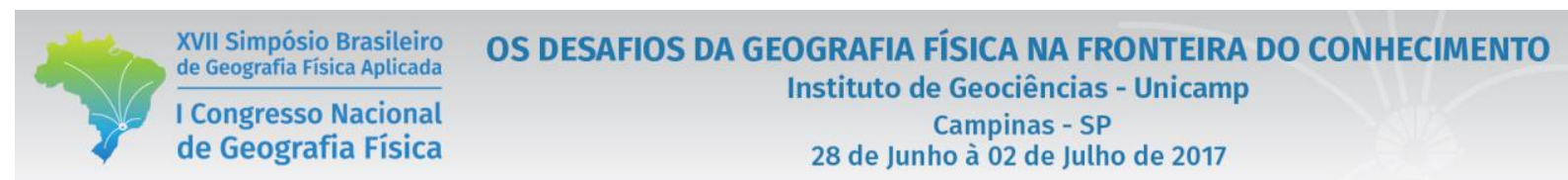

hipsométrico e de declividade da área de estudo, sendo ainda localizado no mapa de declividade as linhas de corte e os respctivos perfis topográficos A-A', B-B', C-C' e D-D'.

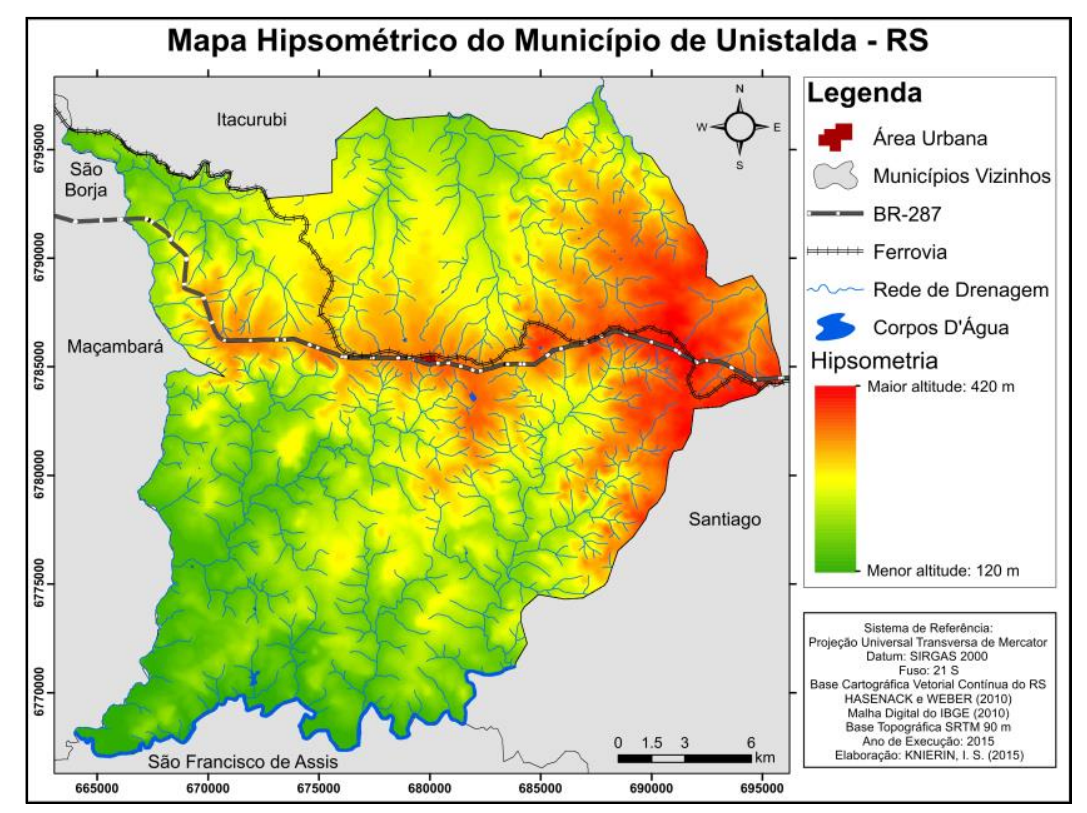

Figura 4 - Mapa hipsométrico do município de Unistalda - RS.

Fonte: KNIERIN, I.S. (2015).

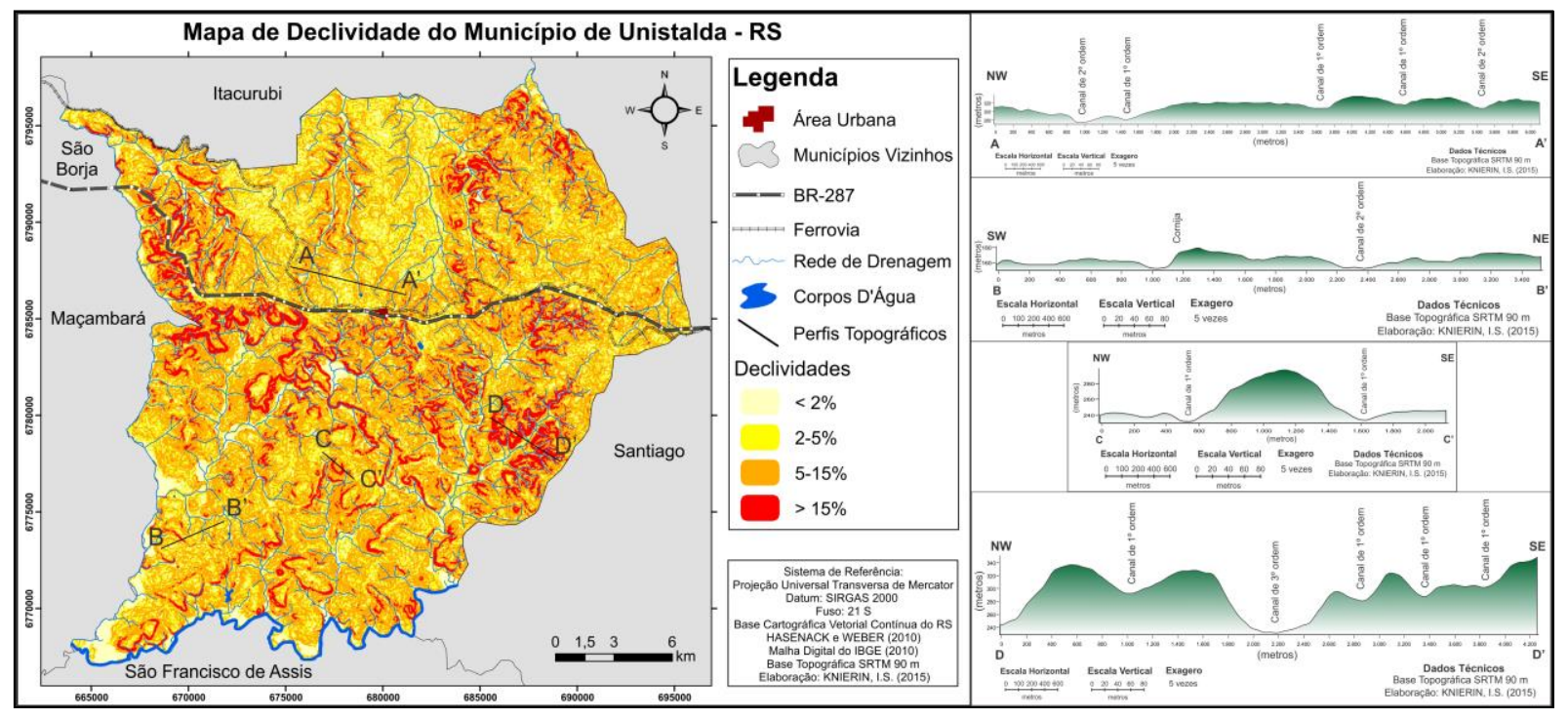

Figura 51 - Mapa de declividade e de localização dos perfis topográficos do município de Unistalda - RS.

Fonte: KNIERIN, I.S. (2015). 


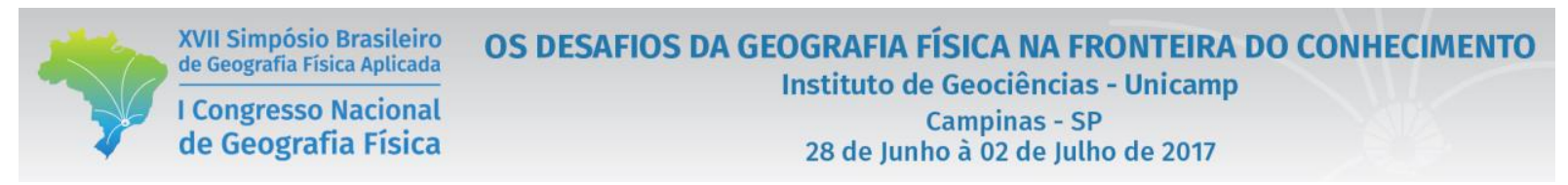

A partir disso, foi possível definir e zonear cinco áreas com padrões de formas e processos semelhantes na área de estudo, conforme pode ser visualizado na Figura 6 e Tabela 2 respectivamente, com a distribuição espacial e quantificação das unidades de relevo da área de estudo.

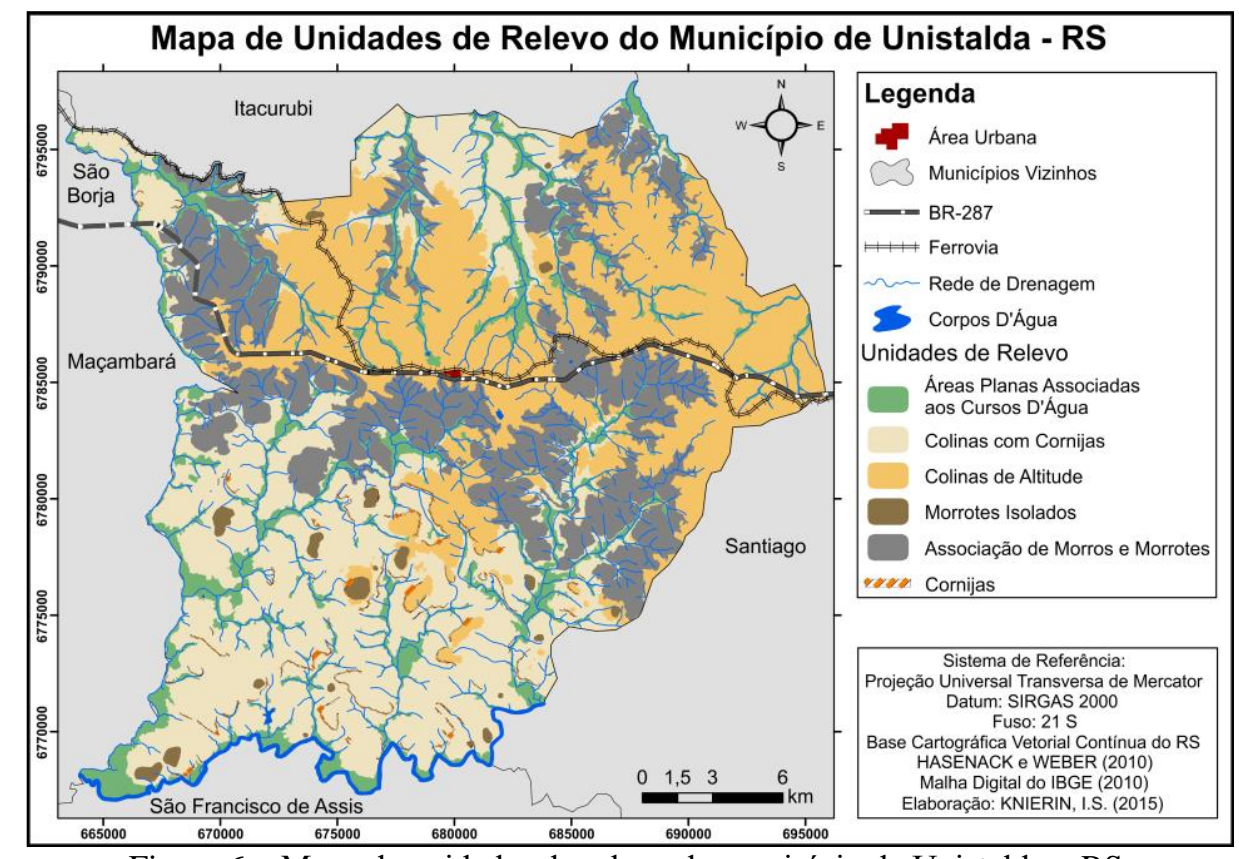

Figura 6 - Mapa de unidades de relevo do município de Unistalda - RS.

Fonte: KNIERIN, I.S. (2015).

Tabela 2 - Quantificação das unidades de relevo do município de Unistalda - RS.

\begin{tabular}{ccc}
\hline Unidades de Relevo & Área em $\mathrm{km}^{2}$ & Área em \% \\
\hline Áreas Planas Associadas aos Cursos D'Água & 75,89 & 12,60 \\
Colinas com Cornijas & 209,30 & 34,75 \\
Colinas de Altitude & 183,66 & 30,49 \\
Morrotes Isolados & 5,87 & 0,97 \\
Associação de Morros e Morrotes & 127,66 & 21,19 \\
\hline
\end{tabular}

Fonte: KNIERIN, I.S. (2015).

A unidade Áreas Planas Associadas aos Cursos D’Água cobre 12,60\% do total do município de Unistalda - RS e corresponde as porções de terreno predominantemente associadas aos principais cursos d'água, em maior hierarquia fluvial da área de estudo. As vertentes possuem declividades inferiores a 5\%, com amplitudes altimétricas que não ultrapassam os $20 \mathrm{~m}$.

Nas áreas de drenagem do Arroio Iguariaçá, Restinga de Santa Maria e os afluentes de até $4^{\circ}$ ordem do Rio Itacurubi se associam, predominantemente com vales encaixados, condicionados a lineamentos 
XVII Simpósio Brasileiro

de Geografia Fisica Aplicada

I Congresso Nacional

de Geografia Física
OS DESAFIOS DA GEOGRAFIA FÍSICA NA FRONTEIRA DO CONHECIMENTO

Instituto de Geociências - Unicamp

Campinas - SP

28 de Junho à 02 de Julho de 2017

estruturais na área de estudo (Figura 7 - A). Já nos sistemas do Arroio Itu-Mirim, afluentes de até $3^{\circ}$ ordem do Rio Itu e o Arroio da Porteirinha, observa-se cursos fluviais de padrão de drenagem dendrítico, ora associados a fraturas marcando segmentos encaixados com padrão retangular (Figura 7 - B).

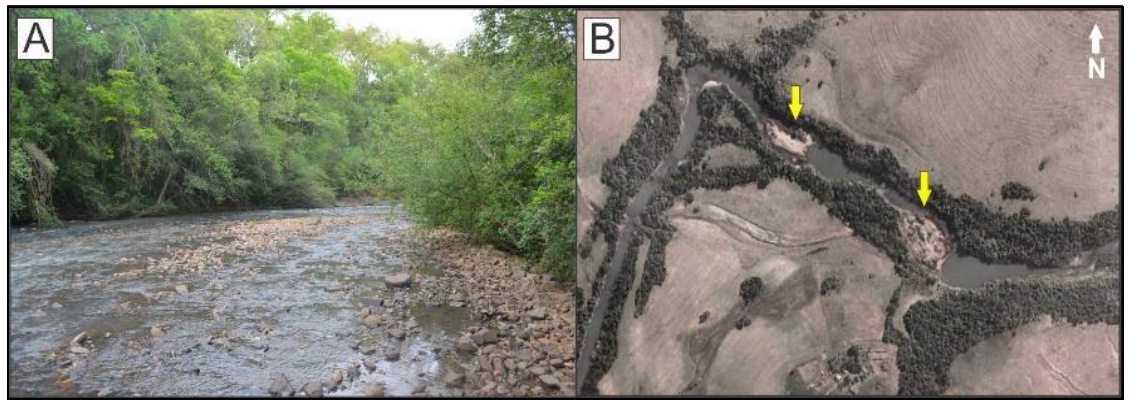

Figura 7 - (A) Médio curso da Restinga de Santa Maria, porção Norte do município de Unistalda - RS. (B) Imagem apresentando a planície do rio Itu e a forma da drenagem que indica controle estrutural e a formação de bancos de areia.

Fonte: KNIERIN, I.S. (2015); adaptado do Google Earth Pro (2015).

A unidade das Colinas com Cornijas cobre 34,75\% da área total do município de Unistalda - RS, recorrente em todos os sistemas de drenagens, mas apresenta-se de maneira mais significativa junto ao Arroio Itu-Mirim, nos afluentes de até $3^{\circ}$ ordem do Rio Itu, no Arroio da Porteirinha e na Restinga de Santa Maria.

$\mathrm{Na}$ área de estudo, essas colinas são delimitadas pela altitude, com cotas altimétricas inferiores aos $250 \mathrm{~m}$. As vertentes são levemente onduladas a onduladas, com declividades médias de 7\%, amplitudes altimétricas de 20 a $60 \mathrm{~m}$ e com comprimentos de vertentes distribuídos predominantemente entre os 700 e $2500 \mathrm{~m}$ (Figura 8 - A e B).

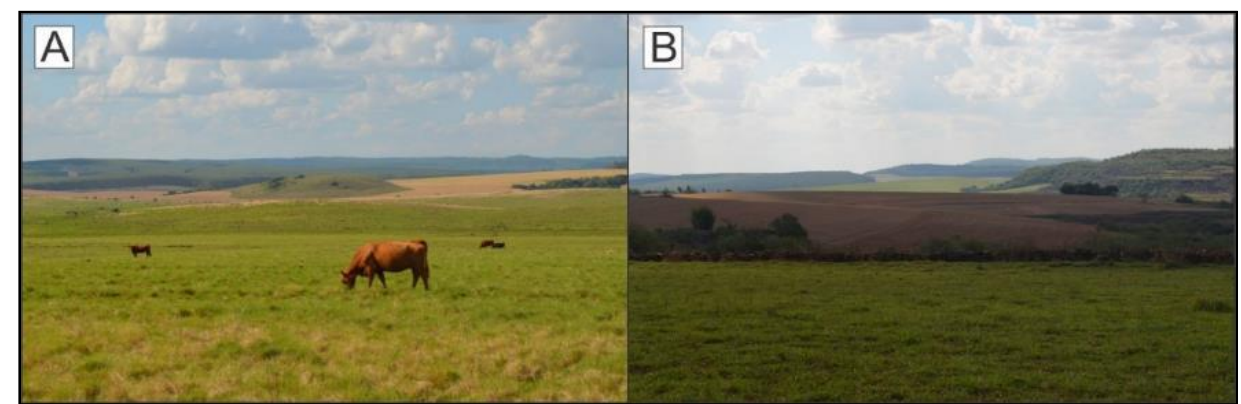

Figura 8 - (A) Área de campo com pecuária extensiva, localizada a Sudoeste do município de Unistalda - RS; (B) Área de solo exposto associado aos diferentes estágios do plantio na porção Oeste da área de estudo.

Fonte: KNIERIN, I.S. (2015). 


\section{OS DESAFIOS DA GEOGRAFIA FÍSICA NA FRONTEIRA DO CONHECIMENTO \\ Instituto de Geociências - Unicamp \\ Campinas - SP \\ 28 de Junho à 02 de Julho de 2017}

Nessa unidade são identificadas feições superficiais denominadas cornijas, que decorrem da maior resistência de camadas litológicas aos processos exógenos. Em função disso, conferem "quebras" do terreno, em faixas com declividades superiores a 15\%, em alguns casos com afloramento das rochas e com encostas vegetadas (Figura 9).

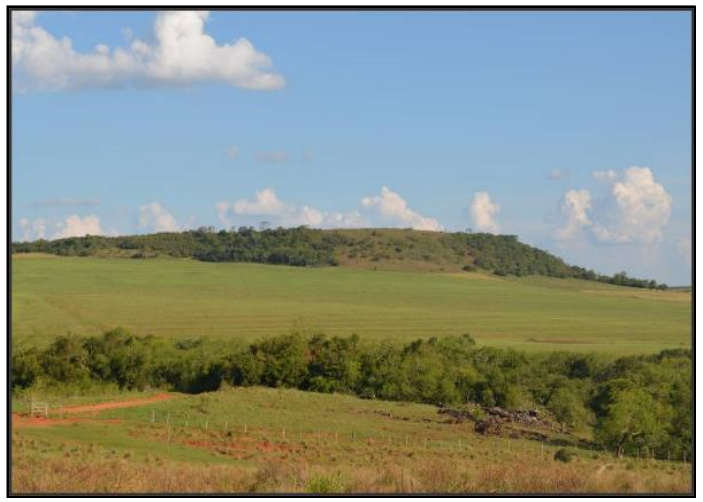

Figura 9 - Área de colina com campo e cornija vegetada ao fundo, localizada na porção Centro-Sudeste do município de Unistalda - RS.

Fonte: KNIERIN, I.S. (2015).

A unidade das Colinas de Altitude cobre a segunda maior área no município, em 30,49\% de sua área total. Essa unidade integra a todas as bacias hidrográficas delimitadas na área do município, mas com maiores áreas associadas aos sistemas de drenagem do Rio Icamaquã, com o Arroio Iguariaçá, Restinga de Santa Maria e os afluentes de até $4^{\circ}$ ordem do Rio Itacurubi. Em menores áreas, as colinas de altitude integram em faixa com direção Centro-Sul da área de estudo, junto o Arroio Itu-Mirim, Arroio da Porteirinha e afluentes de até $3^{\circ}$ ordem do Rio Itu, na qual apresenta-se junto aos altos cursos dos mesmos. As colinas de altitude são delimitadas a partir de altitudes superiores a cota altimétrica de $250 \mathrm{~m}$ na área de estudo, na qual constitui-se por formas de relevo levemente ondulado a ondulado, com declividades médias de 6\%, amplitudes altimétricas de 20 aos $60 \mathrm{~m}$ e comprimentos de vertentes distribuídos predominantemente dos 600 aos 2800 m (Figura 10 - A e B).

A unidade dos Morrotes Isolados cobre $0,97 \%$ da área de estudo e, se localizam, especialmente, em áreas drenadas pelo Arroio Itu-Mirim, afluentes de até $3^{\circ}$ ordem do Rio Itu e Arroio da Porteirinha, como também, nas áreas drenadas pela Restinga de Santa Maria e Arroio Iguariaçá. Essa unidade apresenta menor área no município de Unistalda - RS com formas de relevo que marcam o recuo da área de escarpa do Planalto Sul-Rio-Grandense mais ao norte pela ação erosiva. 


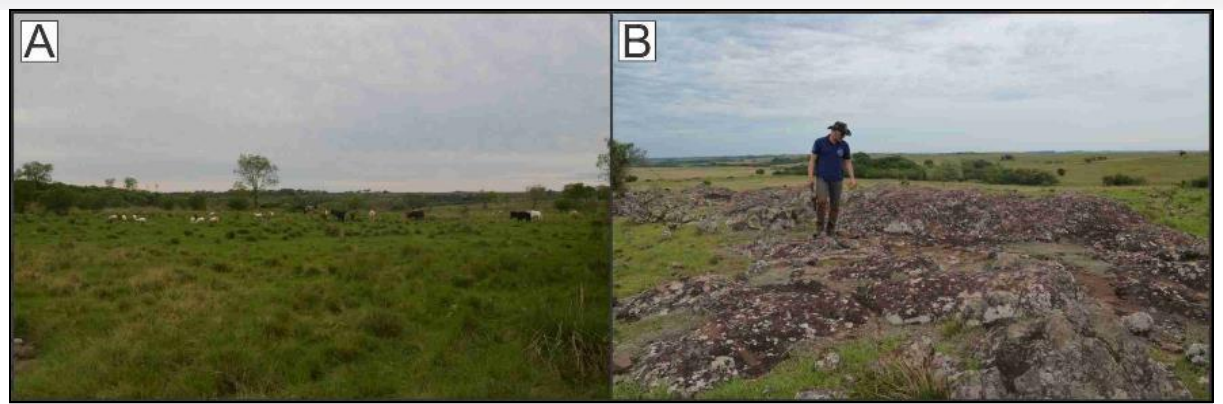

Figura 10 - (A) Área de colinas, com relevo levemente ondulado e campos com uso assoado a pecuária extensiva diversificada; (B) Área de colinas levemente onduladas, com afloramento de topo de derrame vulcânico e campos ao fundo. Fotografias localizadas ao Norte do município de Unistalda - RS.

Fonte: KNIERIN, I.S. (2015).

Apresentam declividades superiores aos $15 \%$ e amplitudes altimétricas que variam predominantemente dos 30 aos $50 \mathrm{~m}$, com comprimentos de vertente, que em alguns casos chegam aos $500 \mathrm{~m}$ aproximadamente. De maneira geral, possuem topos planos ou convexos, de acordo com as litologias constituintes. Ainda da base dessas formas de relevo podem ocorrer processos erosivos lineares, na forma de ravinas e voçorocas (Figura 11).

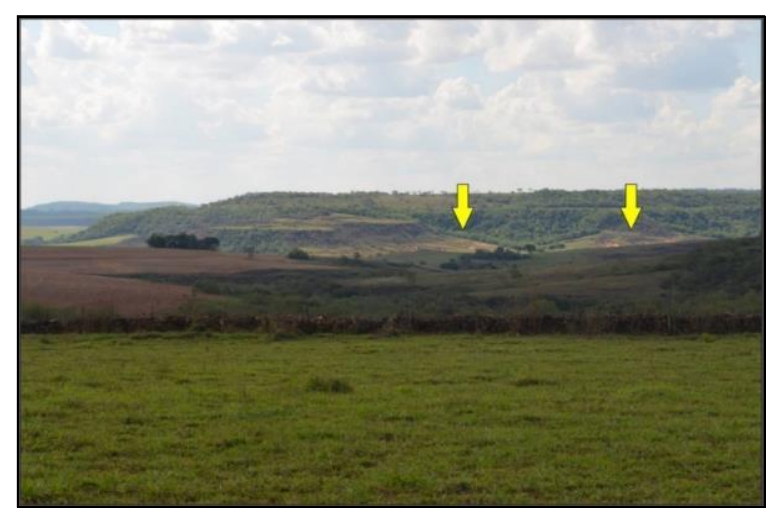

Figura 11 - Área de colina com campo e área de solo exposto com morrotes ao fundo e ocorrência de processos erosivos lineares na base das encostas (flechas amarelas) na porção Oeste do município de Unistalda - RS.

Fonte: KNIERIN, I.S. (2015).

A unidade Associação de Morros e Morrotes cobre 21,19\% do município de Unistalda - RS, localiza-se a Nordeste, Norte e Noroeste, como também em uma linha de interflúvio que se estende na faixa central da área de estudo com direção de Leste a Oeste (Figura 12). 


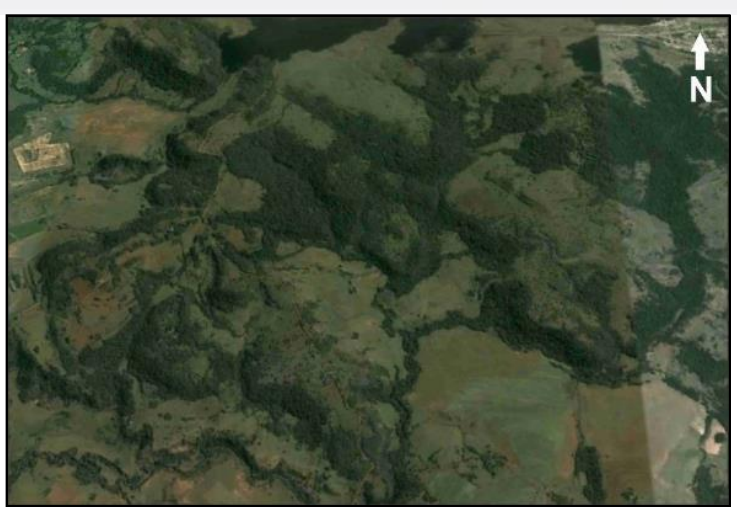

Figura 12 - Visão obliqua de área com associação de morros e morrotes, em porção central do município de Unistalda - RS.

Fonte: Adaptado do Google Earth Pro (2015).

Os morros são definidos por formas de relevo com declividades superiores a $15 \%$ e com amplitudes altimétricas superiores aos $100 \mathrm{~m}$ e comprimentos de vertentes distribuídos entre os 400 aos $1500 \mathrm{~m}$ aproximadamente. Já os morrotes, representam vertentes com declividades superiores a $15 \%$ mas que, no entanto, não ultrapassam os $100 \mathrm{~m}$ de amplitude e os comprimentos podem chegar aos $500 \mathrm{~m}$ em alguns casos.

Por fim, quanto a definição das unidades de relevo no município de Unistalda - RS, a proposta metodológica mostrou-se bastante eficiente, visto que as cinco unidades definidas representam as formas de relevo regionais do município e, a partir dos trabalhos de campo, pode-se constatar a representatividade espacial das unidades definidas. Destaca-se ainda que o mapeamento realizado, aplica-se à escalas aproximadas de 1:50.000, desta forma, situações pontuais podem divergir da situação cartográfica apresentada, porém, a nível de município o mapa apresentado possui muito boa representatividade.

\section{Considerações Finais}

Neste trabalho buscou-se realizar o estudo das formas de relevo para o município de Unistalda - RS, e para isso se baseou na análise de parâmetros morfométricos do relevo. A partir dessas informações, foi possível identificar áreas com características mínimas de heterogeneidade na paisagem, com padrões de formas e processos semelhantes.

Com base na adoção de um modelo digital de elevação oriundo a imagem de RADAR SRTM, e com suporte do SIG e de técnicas de Geoprocessamento, tornou-se possível a modelagem de parâmetros morfométricos para o relevo e a identificação de cinco unidades: Áreas Planas Associadas aos Cursos 


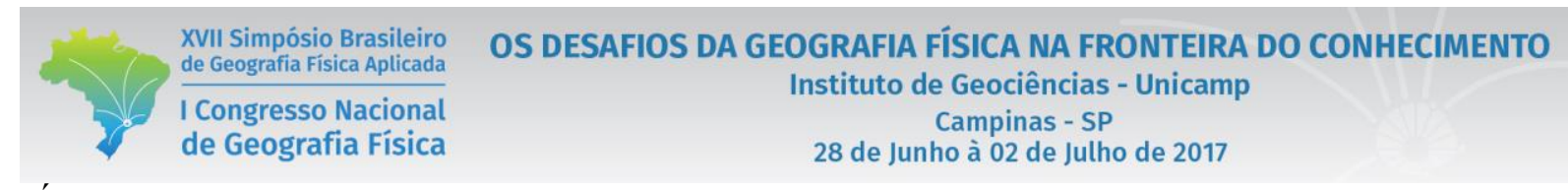

D’Água, Colinas com Cornijas, Colinas de Altitude, Morrotes Isolados e Associação de Morros e Morrotes.

Os dados obtidos neste trabalho foram satisfatórios, considerando as validações realizadas durante os trabalhos de campo na área de estudo. $\mathrm{O}$ zoneamento em unidades de relevo apresenta potencial para estabelecer formas de uso e ocupação da terra e, integrado a isso, permite indicar potencialidades e fragilidades naturais para cada unidade de relevo.

\section{Bibliografia}

CASSETI, V. Elementos de geomorfologia. Goiânia: Editora da UFG, p. 137, 1994.

FLORENZANO. T. G. Introdução à Geomorfologia. In: FLORENZANO. T. G. (Org.). Geomorfologia: conceitos e tecnologias atuais. São Paulo: Oficina de Textos, pp. 11-30, 2008.

GIRÃO, O; CORRÊA, A. C. B. A contribuição da geomorfologia para o planejamento da ocupação de novas áreas. Revista de Geografia. Recife: UFPE DCG/NAPA, v. 21, n. 2, 2004.

GOOGLE EARTH PRO. Interface do usuário. 2015. Disponível em: < https://www.google.com.br/intl/ptBR/earth/>. Acesso em 01 nov. 2015.

GUERRA, A. J. T.; MARÇAL, M. S. Geomorfologia Ambiental. Rio de Janeiro: Bertrand Brasil, 2014.

HASENACK, H.; WEBER, E. Base Cartográfica Vetorial Contínua do Rio Grande do Sul. Porto Alegre: UFRGS Centro de Ecologia, p. 21, 2010.

INSTITUTO DE PESQUISAS TECNOLÓGICAS (IPT). Mapeamento Geomorfológico do Estado de São Paulo. São Paulo. Escala 1:500.000, v. 2. p. 130, 1981.

ROBAINA, L. E. S., TRENTIN, R., BAZZAN, T., RECKZIEGEL, E. W., VERDUM, R., DE NARDIN, D. Compartimentação Geomorfológica da Bacia Hidrográfica do Ibicuí, Rio Grande do Sul, Brasil: Proposta de Classificação. Revista Brasileira de Geomorfologia, v.11, n.2, 2010.

ROSS, J. L. S. Geomorfologia: Ambiente e Planejamento. São Paulo: Contexto, 2014.

SANTOS FILHO, R. D. Antropologia Urbana. In: GUERRA, A. J. T. (Org.). Geomorfologia Urbana. Rio de Janeiro: Bertrand Brasil, 2011.

SILVEIRA, C. T.; SILVEIRA, R. M. P. Classificação geomorfométrica de unidades morfológicas do relevo no Estado do Paraná obtida de atributos topográficos e árvore de decisão. Anais do XV Simpósio Brasileiro de Geografia Física Aplicada. Vitória/ES. 2013.

STRAHLER, A. N. Hypsometric (area-altitude) analysis and erosional topography. Geological Society of America Bulletin, v. 63, p. 1117-1142, 1952.

VALERIANO, M. M. Curvatura vertical de vertentes em microbacias pela análise de modelos digitais de elevação. Campina Grande. Revista Brasileira de Engenharia Agrícola e Ambiental, Campina Grande, v. 7, n. 3, p. 539546, 2003. 


\begin{tabular}{|c|c|}
\hline $\begin{array}{l}\text { XVII Simpósio Brasileiro } \\
\text { de Geografia Fisica Aplicada }\end{array}$ & $\begin{array}{c}\text { OS DESAFIOS DA GEOGRAFIA FÍSICA NA FRONTEIRA DO CONHECIMENTO } \\
\text { Instituto de Geociências - Unicamp }\end{array}$ \\
\hline $\begin{array}{l}\text { I Congresso Nacional } \\
\text { de Geografia Física }\end{array}$ & $\begin{array}{l}\text { Campinas - SP } \\
28 \text { de Junho à } 02 \text { de Julho de } 2017\end{array}$ \\
\hline
\end{tabular}

VALERIANO, M. M. Dados Topográficos. In: FLORENZANO. T. G. (Org.) Geomorfologia: conceitos e tecnologias atuais. São Paulo: Oficina de Textos, pp. 72-104, 2008.

\section{Agradecimentos}

Agradecimento ao Programa de Pós-Graduação em Geografia da Universidade Federal de Santa Maria e aos órgãos de fomento para o desenvolvimento da pesquisa CAPES e CNPQ, pela obtenção das bolsas de estudos. 